\title{
Age-related differences in automatic stimulus- response associations: Insights from young and older adults' parity judgments
}

\author{
LUDOVIC FABRE \\ CNRS and Université de Provence, Marseille, France \\ and \\ PATRICK LEMAIRE \\ CNRS, Université de Provence, and Institut Universitaire de France, Marseille, France
}

\begin{abstract}
Young and older adults completed a parity judgment task (i.e., judging whether a target digit was odd or even) in which target numbers were preceded by masked prime numbers presented for $43 \mathrm{msec}$. Targets were either congruent (i.e., they had the same parity status as their primes) or incongruent (i.e., odd primes were paired with even targets, and even primes were paired with odd targets). Response times, percent errors, and event-related potentials (ERPs) were recorded for all items to compare automatic stimulus-response association (ASRA) and congruence effects (i.e., better performance on congruent than on incongruent trials) across age groups. Two important original sets of findings were obtained in this sample of participants. First, both age groups showed ASRA effects in behavioral measures. Second, age-related differences were observed in amplitude, timing, and scalp distributions for each congruent and incongruent ERP. These findings have implications for furthering the understanding of ASRA effects and of general characteristics of cognitive processes affected (or not affected) by aging.
\end{abstract}

Aging is associated with decreased performance in a wide variety of cognitive domains (see Craik \& Salthouse, 2000). However, not all cognitive processes are disrupted with aging. Research on cognitive aging aims to characterize which processes are disrupted by aging and which remain intact. One suggestion is that controlled processes (such as those involved in many memory tasks) would be affected by age whereas automatic processes (such as those involved in priming experiments) would be spared. Evidence of age-related changes in controlled processes in most cognitive domains has been reported. However, evidence of age-related invariance in automatic processes is mixed: Some findings are consistent with no effects of age on automatic processes, and others suggest disrupted automatic processes with age. In the present experiment, we tested effects of age on automatic processes using a different approach from those of previous studies.

Findings reported by Balota and colleagues suggest age-related invariance in automatic processes. For example, in a naming task, Balota, Black, and Cheney (1992)

\footnotetext{
This research was supported by a grant awarded to P.L. from the Cognitique program of the French Ministère de la Recherche and a graduate fellowship awarded to L.F. from the Institut Universitaire de France. We thank Marc Brysbaert, Bernard Hommel, and two anonymous reviewers for useful comments on previous versions of the manuscript. Correspondence concerning this article should be addressed to P. Lemaire, Université de Provence, 3, place Victor Hugo, 13331 Marseille cedex 3, France (lemaire@up.univ-mrs.fr).
}

reported smaller semantic priming effects in older adults in comparison with young adults at long stimulus onset asynchronies (SOAs; i.e., 1,750 msec) and comparable priming effects between these age groups at short SOAs (i.e., $250 \mathrm{msec}$ ). They argued that attentional mechanisms, tapped at long prime-target SOAs, produced some breakdown, whereas automatic activation, tapped at short prime-target SOAs, did not. They concluded that agerelated changes appeared to be more likely to occur in the attentional component of priming than in its automatic component (see Duchek \& Balota, 1993, for a review).

Other findings suggest that age leads to disrupted automatic processes. For example, Howard, Shaw, and Heisey (1986) found semantic priming effects (i.e., shorter response times [RTs] on associated than on unassociated prime-target stimuli) in young and older participants when targets were presented at least $450 \mathrm{msec}$ after primes. In the 150 -msec SOA condition, only young participants showed priming effects, suggesting that the automatic spreading activation underlying these semantic priming effects was impaired in older adults.

One possible source of discrepancy between studies on age-related changes in priming effects concerns how participants used primes during target processing. Although strategic effects are known to arise at long SOAs (Neely, 1991), it remains possible that age-related differences in SOAs as short as 150 msec stem from young adults' using information from primes to process targets or to deliberate on guessing strategies and older adults' not doing so. One possible way to control for such potential differences in how primes 
are used across age groups is to test subliminal priming or automatic stimulus-response association (ASRA) effects.

ASRA, or subliminal priming effects, are observed when primes are very briefly presented (i.e., for less than 50 or $60 \mathrm{msec}$ ). Participants are not aware of primes and cannot consciously use information from them when processing targets. Nevertheless, the presence of priming effects is indicated by faster performance on targets when primes and targets are related than when they are not related. When primes are briefly presented, the cognitive system automatically activates codes of associated responses (Hommel, 1998a, 1998b). When these responses are congruent with responses to be given on targets, people respond more quickly than when responses automatically activated on primes mismatch those to be given on targets.

ASRA effects are good candidates for testing aging effects on automatic processes. They have been observed in different tasks and in different domains (see, e.g., Kinoshita \& Lupker, 2003, for a recent review), including lexical decision (see, e.g., Forster \& Davis, 1984), pictorial (see, e.g., Dell'Acqua \& Grainger, 1999), and arithmetic (see, e.g., Dehaene et al., 1998; Kunde, Kiesel, \& Hoffmann, 2003; Reynvoet, Caessens, \& Brysbaert, 2002) tasks, and at varying levels of prime duration (see, e.g., Draine \& Greenwald, 1998).

In the present study, we tested ASRA effects in numerical judgment tasks because previous data showed robust ASRA effects in such tasks (Dehaene et al., 1998; Koechlin, Naccache, Block, \& Dehaene, 1999; Naccache, Blandin, \& Dehaene, 2002; Naccache \& Dehaene, 2001; Reynvoet \& Brysbaert, 1999; Reynvoet et al., 2002). For example, Reynvoet et al. asked participants to determine if target digits were odd or even; primes presented for $43 \mathrm{msec}$ influenced RTs to targets. RTs to targets were longer on incongruent trials (i.e., trials in which primes and targets had different parity statuses) than on congruent trials (i.e., trials in which primes and targets were either both odd or both even).

ASRA effects are tested in a parity judgment task accomplished by young and older adults. We collected data on both behavioral performance and event-related potentials (ERPs). ERPs permitted us to compare brain activity between congruent and incongruent trials in young and older adults. Previous works showed that N400, a negative component of brain waves that occur with a maximum amplitude around $400 \mathrm{msec}$ after stimulus display, is influenced by factors such as semantic associations (see, e.g., Brown, Hagoort, \& Chwilla, 2000; Deacon, Hewitt, Yang, \& Nagata, 2000; Dehaene et al., 1998; Ruz, Madrid, Lupiáñez, \& Tudela, 2003) and is larger for incongruent than for congruent trials. Moreover, following Hamberger, Friedman, Ritter, and Rosen's (1995) findings of an agerelated decrease in N400, differences between incongruent and congruent N400 waves were expected to be smaller and to occur later in older adults.

\section{METHOD}

Participants. Eleven young adults ( 6 women) with a mean age of 24.4 years (range, $21-30$ years) and 11 older participants (5 women) with a mean age of 69.1 years (range, 61-82 years) were tested. Undergraduates at the University of Provence and older adults were recruited on a voluntary basis. The difference between mean number of school years in the young (14.3 years) and the older (12.9 years) adults was not significant $\left[F(1,10)=1.92, M S_{\mathrm{e}}=7.9\right]$. All of the older adults took the Mini-Mental State Examination for dementia screening (Folstein, Folstein, \& McHugh, 1975). All the individuals had scores higher than $28(M=29.2)$; therefore, none was excluded. All of the participants reported normal or corrected-tonormal vision.

At the end of the experiment, the participants took a French version of the Mill Hill Vocabulary Scale (MHVS) to assess their verbal ability (Deltour, 1993). The mean scores on the MHVS differed significantly between the young $(25.2, S D=4.4)$ and the older $(29.7, S D=2.5)$ participants $\left[F(1,10)=7.66, M S_{\mathrm{e}}=14.8\right]$. The participants also completed with paper and pencil the addition and subtraction-multiplication subtests in French, Ekstrom, and Price's (1963) kit as an assessment of their arithmetic skills. Addition and subtraction-multiplication mean scores were comparable between the young $(82, S D=24.2)$ and the older $(99.2, S D=25.6)$ participants $\left[F(1,10)=3.74, M S_{\mathrm{e}}=434.7\right]$.

Stimuli and Procedure. Prime stimuli were number words (e.g., FIVE). Target stimuli were Arabic numerals (e.g., "6") or number words (e.g., SIX). All stimuli were written numbers from 2 to 9 and were presented in 24-point Courier New font. Parity compatibility between prime and target was manipulated in this experiment. Half of the trials were congruent (i.e., primes and targets were both even or both odd), and half were incongruent (i.e., prime was even and target was odd, or vice versa). To respond, the participants had to press one of two response keys (L or S) on an AZERTY keyboard.

The parity judgment task included two parts. In one part, the participants pressed the L key to respond "odd" and the S key to respond "even." In the other part, they did the reverse. Each part began with a practice block of 25 trials and included four blocks of 64 trials each: The first two blocks included word format targets, and the following two blocks included digit format targets. The orders of the parts and of the blocks were determined for each participant using a Latin square design. All the participants completed 512 trials (in addition to 50 practice trials). Each trial consisted of the presentation of a numeral prime for a very short duration $(43 \mathrm{msec})$. The prime was masked by two nonsense letter strings and followed by another numeral target (Figure 1).

To test whether conscious information was available from prime stimuli in this presentation condition, we collected subjective reports of individuals. We asked the participants if they had any comments on the experiment. Then, we asked them if they had seen a masked word after the presentation cross. None of them had clearly distinguished the primes. Moreover, a new group of 13 young participants performed a judgment parity task on the same 512 prime stimuli in the absence of target stimuli. The success rate (mean $51 \%$ ) did not significantly differ from the $50 \%$ value expected by chance $[t(12)=1.21]$.

Electroencephalograms (EEGs) were recorded using an ElectroCap (ElectroCap International, Nieuwkoop, The Netherlands) of 32 pure tin electrodes referenced to the left mastoid. Electrode locations covered the entire scalp and were defined by extrapolating the international 10-20 system. We presented trials on a standard PC-compatible SVGA monitor (70-Hz refresh). The EEG was digitized at $200 \mathrm{~Hz}$ with a baseline of $100 \mathrm{msec}$. The horizontal electrooculogram (EOG) was recorded with an electrode placed to the right of the external canthus. The vertical EOG was recorded from an electrode beneath the left eye. Trials containing ocular artifacts, movement artifacts, or amplifier saturation were excluded from the average ERP waveform $(22.1 \%$ of the trials for young adults and $24 \%$ of the trials for older adults, including incorrect responses; $F<1$ ), leaving enough remaining trials (minimum $N=113$ ) for analysis. The EEG and EOG were amplified by an SA Instrumentation amplifier with a band-pass filtered at $0.1-30 \mathrm{~Hz}$ and digitized at $200 \mathrm{~Hz}$ by a PC-compatible microcomputer. 


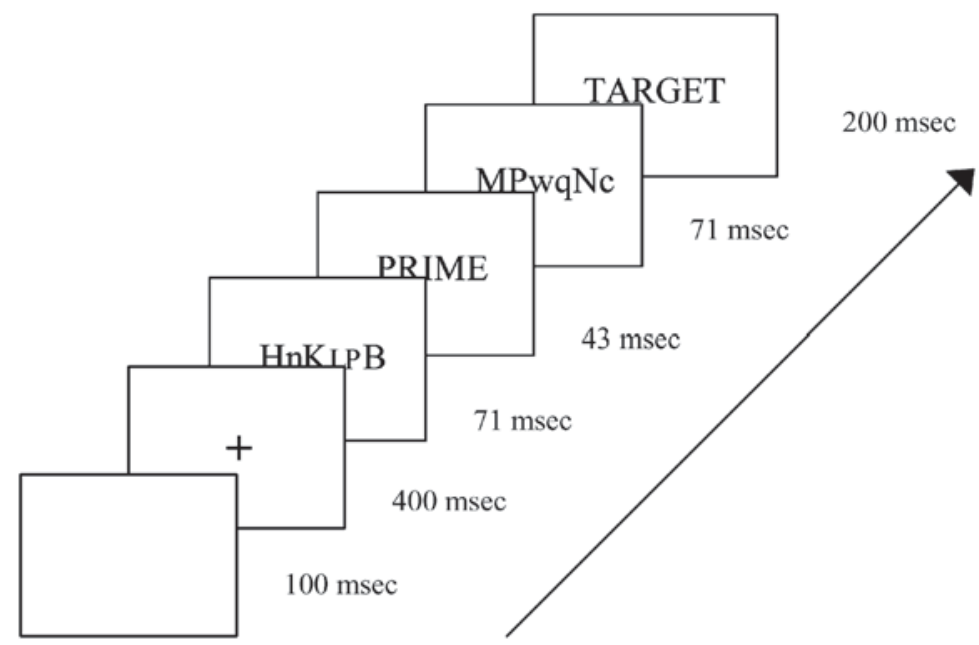

Figure 1. Sequence of events within a given trial.

\section{RESULTS}

Unless otherwise noted, all results were significant at $p<.05$.

\section{Behavioral Data}

For each participant, RTs more than $1.96 S D$ above the mean were replaced by the mean RT of the corresponding individual $(0.6 \%$ and $2.4 \%$ of trials for the young and the older participants, respectively). ${ }^{1}$ RTs and percent errors were submitted to ANOVAs with target notation (digit vs. word format) $\times$ congruence (congruent vs. incongruent) as within-participants factors and age (young vs. older) as a between-participants factor. As can be seen in Table 1, the young participants were $157 \mathrm{msec}$ faster than the older participants $\left[F(1,20)=10.69, M S_{\mathrm{e}}=0.1\right]$. The participants responded $51 \mathrm{msec}$ faster with digit format than with word format $\left[F(1,20)=105.58, M S_{\mathrm{e}}=0.0005\right]$ and $17 \mathrm{msec}$ faster on congruent than on incongruent trials $\left[F(1,20)=23.05, M S_{\mathrm{e}}=0.0003\right]$. Within each age group, ANOVAs confirmed significant congruence effects of $15 \mathrm{msec}$ for the young participants $[F(1,14)=15.69$, $\left.M S_{\mathrm{e}}=0.00008\right]$ and $20 \mathrm{msec}$ for the older participants ${ }^{2}$ $\left[F(1,14)=9.74, M S_{\mathrm{e}}=0.0002\right] .^{3}$
RT distributions (see Figure 2) revealed that congruence effects were not the result of averaging. All but 2 young and 1 older adult showed positive congruence effects ranging from 1 to $66 \mathrm{msec}$. Analyses of percent errors showed no significant effects $(F \mathbf{s}<1)$, possibly because of very low error rates.

\section{EEG}

The onset time of the divergence between congruent and incongruent waves was estimated by a statistical method proposed by Rugg, Doyle, and Melan (1993). It was defined by the latency during which we observed eight consecutive significant $t$ values $(p<.05)$ when testing the hypothesis of nondifference between two conditions for a single electrode. ${ }^{4}$ We estimated the onset time on the $\mathrm{Pz}$ electrode and obtained two different temporal windows for the young and the older participants. The outcomes of the $t$ tests revealed divergences of 370-485 and 495-550 msec after target presentation for the young and the older adults, respectively. These time windows were centered on the maximal size effect. In these intervals, the incongruent waves were more negative than the congruent waves.

To compare the activations between the young and the older participants, analyses were performed on the N400

Table 1

\begin{tabular}{|c|c|c|c|c|c|c|c|c|c|}
\hline \multirow{3}{*}{$\begin{array}{c}\text { Target } \\
\text { Format }\end{array}$} & \multirow[b]{3}{*}{ Age } & \multicolumn{5}{|c|}{ Response Time } & \multirow{2}{*}{\multicolumn{3}{|c|}{ Percent Errors }} \\
\hline & & \multicolumn{2}{|c|}{ IP } & \multicolumn{2}{|c|}{$\mathrm{CP}$} & \multirow[b]{2}{*}{ Difference } & & & \\
\hline & & $M$ & $S D$ & $M$ & $S D$ & & IP & $\mathrm{CP}$ & Difference \\
\hline \multirow[t]{3}{*}{ Digit } & Young & 503 & 91 & 486 & 95 & 17 & 9.5 & 8.1 & 1.4 \\
\hline & Older & 672 & 113 & 651 & 112 & 21 & 7.9 & 8.9 & -1.0 \\
\hline & Mean & & & & & 19 & 8.7 & 8.5 & 0.2 \\
\hline \multirow[t]{3}{*}{ Word } & Young & 562 & 95 & 550 & 101 & 12 & 5.7 & 5.6 & 0.1 \\
\hline & Older & 712 & 105 & 692 & 120 & 20 & 8.5 & 7.5 & 0.9 \\
\hline & Mean & \multicolumn{2}{|c|}{637} & \multicolumn{2}{|c|}{621} & 16 & 7.1 & 6.6 & 0.5 \\
\hline
\end{tabular}

Note-IP, incongruent prime; CP, congruent prime; difference, IP - CP. 

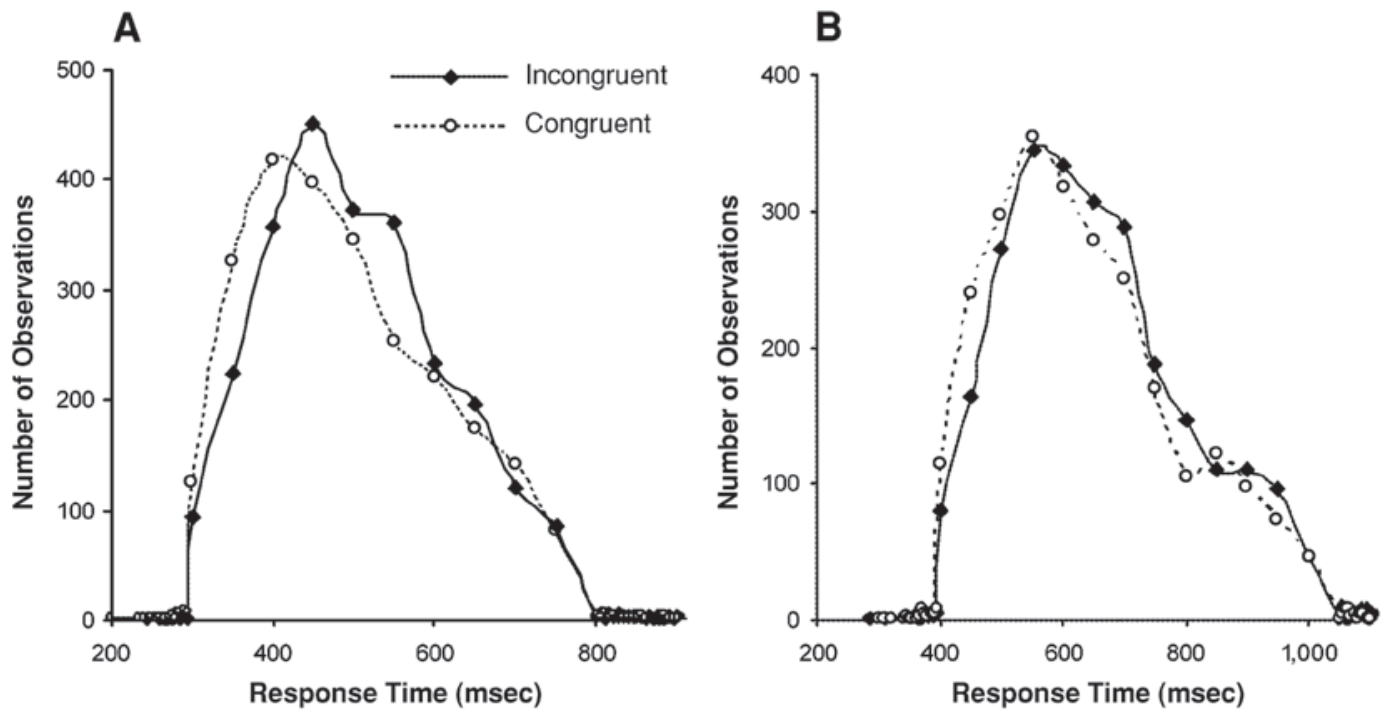

Figure 2. Behavioral priming effects in (A) young participants and (B) older participants. The latency distribution of correct responses showed a rightward shift in incongruent trials relative to congruent trials.

component (Kutas \& Hillyard, 1980). This component typically shows a centroparietal scalp distribution in the visual modality, and it is thought to reflect semantic integration processes. We analyzed three groups of electrodes: a central group $(\mathrm{Cz}, \mathrm{Pz}, \mathrm{Oz})$, a parietal left group (CP1, CP5, P3), and a parietal right group (CP2, CP6, P4). We conducted ANOVAs on the mean amplitude separately for the young and the older adults. For the central group, the design included electrodes and congruence as withinparticipants factors. For parietal electrodes, the design included congruence and side of response (left vs. right) as within-participants factors.

The young participants showed congruence effects in the central $\left[F(1,10)=7.79, M S_{\mathrm{e}}=1.32\right]$ and parietal $\left[F(1,10)=9.48, M S_{\mathrm{e}}=1.08\right]$ groups for the temporal window of 370-485 msec. The amplitude of the incongruent waves was smaller than that of the congruent waves. The amplitude difference was $1.24 \mu \mathrm{V}$ for the central group and $1.3 \mu \mathrm{V}$ for the parietal group. In the parietal group, there was an interaction between congruence and side $\left[F(1,10)=6.92, M S_{\mathrm{e}}=0.03\right]$. The amplitude difference was smaller in the left parietal group $(1.21 \mu \mathrm{V})$ than in the right parietal group $(1.4 \mu \mathrm{V}$; see Table 2 and Figure 3). The older participants showed a divergence of 495-550 msec. We found a congruence effect in the central group $\left[F(1,10)=5.24, M S_{\mathrm{e}}=1.29\right]$. The congruent waves were $0.64 \mu \mathrm{V}$ more positive than the incongruent waves. There were no other significant effects (see Table 2).

The amplitude divergence between congruent and incongruent waves occurred approximately $125 \mathrm{msec}$ later in the older than in the young adults. Moreover, the difference between congruent and incongruent waves was smaller in the older participants than in the young participants $\left[F(1,20)=80.11, M S_{\mathrm{e}}=0.01\right]$ and was localized in the central region (Table 2). The young participants, in contrast, showed a divergence of congruent and incongruent waves in the central and parietal electrodes (see Table 2). To compare windows of equal ranges in both groups, we determined equivalent time windows in the young and older adults from the time when the amplitude difference between congruent and incongruent waves was maximum $\pm 10 \mathrm{msec}$. This maximum appeared 420 and $525 \mathrm{msec}$ after the cross presentation for the young and the older participants, respectively. We conducted separate ANOVAs on the mean amplitude, one for parietal electrodes and one for central electrodes, involving 2 (age) $\times$ 2 (congruence) designs. We obtained significant effects of congruence for the parietal group $[F(1,20)=15.99$, $\left.M S_{\mathrm{e}}=0.8\right]$ and for the central group $[F(1,20)=17.19$, $\left.M S_{\mathrm{e}}=0.3\right]$. There was a significant interaction, showing large differences in the young adults' ERPs for the congruent and the incongruent trials for the parietal group $\left[F(1,20)=5.42, M S_{\mathrm{e}}=0.9\right] .^{5}$

\section{DISCUSSION}

In the present experiment, when targets had the same parity as primes responses were faster than they were with incongruent conditions in both age groups. These findings replicate ASRA effects previously reported in young adults (see, e.g., Dehaene et al., 1998; Reynvoet et al., 2002) and

Table 2

Difference in Amplitude (Congruent Amplitude - Incongruent Amplitude, in $\mu \mathrm{V}$ ) Between Congruent and Incongruent Waves

\begin{tabular}{ccc}
\hline $\begin{array}{c}\text { Groups of } \\
\text { Electrodes }\end{array}$ & $\begin{array}{c}\text { Young Adults } \\
\text { (Range: } 370-485 \mathrm{msec} \text { ) }\end{array}$ & $\begin{array}{c}\text { Older Adults } \\
\text { (Range: } 495-550 \mathrm{msec} \text { ) }\end{array}$ \\
\hline Central & $1.24^{*}$ & $0.64^{*}$ \\
Parietal & $1.3^{*}$ & 0.43 \\
\hline
\end{tabular}

${ }^{*} p<.05$. 


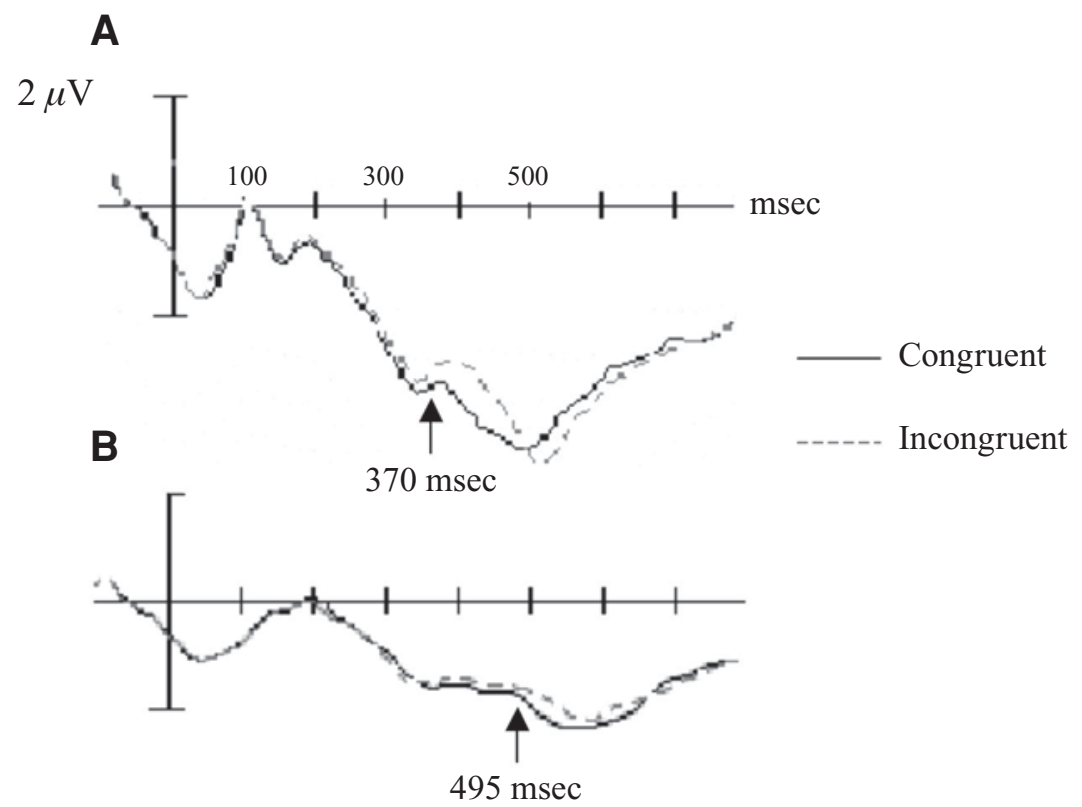

Figure 3. ERP data for one electrode (Pz) in (A) young and (B) older participants. Arrows indicate the beginning of the divergence between congruent and incongruent waves.

extend subliminal priming to older adults. These ASRA effects were also electrophysiologically observed: ERPs were larger for incongruent than for congruent items. Moreover, differences between the young and the older participants were observed in the electrophysiological data. These differences were related to time, amplitude, and scalp distributions of ERPs. Regarding the timing of ERPs, the electrophysiological signature of ASRA effects occurred $125 \mathrm{msec}$ later in the older adults than in the young adults. The difference in amplitude between congruent and incongruent waves was larger in the young adults than in the older adults, and the young participants showed congruence effects in central and parietal areas whereas the older participants showed congruence effects only in central areas.

Age-related differences in time, amplitude, and scalp distributions of ERPs are consistent with previous studies in other cognitive domains or tasks (e.g., Kutas \& Iragui, 1998; Schwartz, Kutas, Butters, Paulsen, \& Salmon, 1996). For example, in a semantic categorization task, Kutas and Iragui showed that N400 effects were observed across the adult lifespan but became reduced in amplitude and more variable with age.

The present data have some implications regarding characterization of age-related changes in human cognition. In the psychology of aging, researchers have used the distinction between automatic and controlled (or attentional) cognitive processes (Posner \& Snyder, 1975; Schneider \& Shiffrin, 1977; Shiffrin \& Schneider, 1977) to categorize processes that are maintained versus those that are disrupted with aging. Previous findings and theories led some researchers to propose that controlled processes would be impaired by aging and automatic processes would be age invariant (Balota et al., 1992; Burke, White, \& Diaz, 1987; Duchek \& Balota, 1993; Hasher \& Zacks, 1979; McDowd \& Shaw, 2000).

The present findings of age-related differences in ASRA effects (often assumed to be one signature of automatic processes) suggest that this distinction between automatic and controlled (or attentional) processes is not sufficient to discriminate between age-invariant processes and processes that are impaired with age. In our experiment, RT data showed that congruence effects are present in both young and older adults as if ASRAs were not impaired with age, which is consistent with the hypothesis of age constancy in automatic processes (see, e.g., Duchek $\&$ Balota, 1993). However, findings of the ERP data revealed age-related changes in these ASRAs. Not only was the amplitude of the congruence effects smaller in the older adults, but the difference in amplitude between the congruent and the incongruent waves was delayed in the older adults.

The difference between RTs and ERPs may come from the RTs' reflecting the end product of cognitive processes in priming, in contrast to the greater temporal resolution of the ERPs. The present findings suggest that ASRA effects involve two mechanisms: automatic activation of information and a nonautomatic mechanism (Naccache et al., 2002). Here, retrieval process would achieve automatic activation of parity information, whereas a nonautomatic mechanism, such as encoding of primes or controlled reaction to priming, would resolve the conflicting parity information between primes and targets (e.g., inhibition of incongruent information). With regard to encoding of primes, the key for future studies is to make sure that the stimulus producing the $\mathrm{N} 400$ is different from the one that 
triggers the decision making (and hence the P300). Such a two-process view of subliminal priming is consistent with effects of temporal manipulations of ASRA effects (Naccache et al., 2002). By testing age-related differences in other forms of subliminal priming and further manipulating temporal parameters of priming procedures in aging research, future works will test the generality of this twoprocess view of subliminal priming and age-related differences in ASRA effects.

\section{REFERENCES}

Balota, D. A., Black, S. R., \& Cheney, M. (1992). Automatic and attentional priming in young and older adults: Reevaluation of the two-process model. Journal of Experimental Psychology: Human Perception \& Performance, 18, 485-502.

Brown, C. M., Hagoort, P., \& Chwilla, D. J. (2000). An eventrelated brain potential analysis of visual word priming effects. Brain \& Language, 72, 158-190.

Burke, D. M., White, H., \& Diaz, D. L. (1987). Semantic priming in young and older adults: Evidence for age constancy in automatic and attentional processes. Journal of Experimental Psychology: Human Perception \& Performance, 13, 79-88.

Craik, F. I. M., \& Salthouse, T. A. (EDs.) (2000). The handbook of aging and cognition (2nd ed.). Mahwah, NJ: Erlbaum.

Deacon, D., Hewitt, S., Yang, C.-M., \& Nagata, M. (2000). Eventrelated potential indices of semantic priming using masked and unmasked words: Evidence that the N400 does not reflect a post-lexical process. Cognitive Brain Research, 9, 137-146.

Dehaene, S., Naccache, L., Le Clec'H, G., Koechlin, E., Mueller, M., Dehaene-Lambertz, G., ET Al. (1998). Imaging unconscious semantic priming. Nature, 395, 597-600.

Dell'Acqua, R., \& Grainger, J. (1999). Unconscious semantic priming from pictures. Cognition, 73, B1-B15.

Deltour, J. J. (1993). Echelle de vocabulaire de Mill Hill de J. C. Raven: Adaptation française et normes européennes du Mill Hill et du Standard Progressive Matrices de Raven (PM38). Braine-le-Château, Belgium: Editions l'Application des Techniques Modernes.

Draine, S. C., \& Greenwald, A. G. (1998). Replicable unconscious semantic priming. Journal of Experimental Psychology: General, 127, 286-303.

DucheK, J. M., \& BALOtA, D. A. (1993). Sparing activation processes in older adults. In J. R. J. Cerella, J. M. Rybash, W. Hoyer, \& M. L. Commons (Eds.), Adult information processing: Limits on loss (pp. 383406). San Diego: Academic Press.

Folstein, M. F., Folstein, S. E., \& McHugh, P. R. (1975). "Mini-mental state": A practical method for grading the cognitive state of patients for the clinician. Journal of Psychiatric Research, 12, 189-198.

Forster, K. I., \& DAVIS, C. (1984). Repetition priming and frequency attenuation in lexical access. Journal of Experimental Psychology: Learning, Memory, \& Cognition, 10, 680-698.

French, J. W., Ekstrom, R. B., \& Price, L. A. (1963). Kit of reference tests for cognitive factors. Princeton: Educational Testing Service.

Hamberger, M. J., Friedman, D., Ritter, W., \& Rosen, J. (1995). Event-related potential and behavioral correlates of semantic processing in Alzheimer's patients and normal controls. Brain \& Language, 48, 33-68.

HASHER, L., \& ZACKS, R. T. (1979). Automatic and effortful processes in memory. Journal of Experimental Psychology: General, 108, 356-388.

Hommel, B. (1998a). Automatic stimulus-response translation in dualtask performance. Journal of Experimental Psychology: Human Perception \& Performance, 24, 1368-1384.

Hommel, B. (1998b). Event files: Evidence for automatic integration of stimulus-response episodes. Visual Cognition, 5, 183-216.

Howard, D. V., Shaw, R. J., \& HeISEy, J. G. (1986). Aging and the time course of semantic activation. Journal of Gerontology, 41, 195-203.

Kinoshita, S., \& LuPKer, S. J. (2003). Priming and attentional control of lexical and sublexical pathways in naming: A reevaluation. Journal of Experimental Psychology: Learning, Memory, \& Cognition, 29, 405-415.
Koechlin, E., Naccache, L., Block, E., \& Dehaene, S. (1999). Primed numbers: Exploring the modularity of numerical representations with masked and unmasked semantic priming. Journal of Experimental Psychology: Human Perception \& Performance, 25, 1882-1905.

Kunde, W., Kiesel, A., \& Hoffmann, J. (2003). Conscious control over the content of unconscious cognition. Cognition, 88, 223-242.

Kutas, M., \& Hillyard, S. A. (1980). Reading senseless sentences: Brain potentials reflect semantic incongruity. Science, 207, 203-205.

Kutas, M., \& IRAGUI, V. (1998). The N400 in a semantic categorization task across 6 decades. Electroencephalography \& Clinical Neurophysiology, 108, 456-471.

McDowd, J. M., \& Shaw, R. J. (2000). Attention and aging: A functional perspective. In F. I. M. Craik \& T. A. Salthouse (Eds.), The handbook of aging and cognition (2nd ed., pp. 221-292). Mahwah, NJ: Erlbaum.

Naccache, L., Blandin, E., \& Dehaene, S. (2002). Unconscious masked priming depends on temporal attention. Psychological Science, 13, 416-424.

Naccache, L., \& Dehaene, S. (2001). Unconscious semantic priming extends to novel unseen stimuli. Cognition, 80, 215-229.

Neely, J. H. (1991). Semantic priming effects in visual word recognition: A selective review of current findings and theories. In D. Besner \& G. Humphreys (Eds.), Basic processes in reading: Visual word recognition (pp. 264-336). Hillsdale, NJ: Erlbaum.

PosNer, M. I., \& SNYDER, C. R. (1975). Attention and cognitive control. In R. L. Solso (Ed.), Information processing and cognition (pp. 5585). Hillsdale, NJ: Erlbaum.

Reynvoet, B., \& Brysbaert, M. (1999). Single-digit and two-digit Arabic numerals address the same semantic number line. Cognition, 72, 191-201.

Reynvoet, B., Caessens, B., \& Brysbaert, M. (2002). Automatic stimulus-response associations may be semantically mediated. Psychonomic Bulletin \& Review, 9, 107-112.

Rugg, M. D., Doyle, M. C., \& Melan, T. (1993). An event-related potential study of the effects of within- and across-modality word repetition. Language \& Cognitive Processes, 8, 357-377.

Ruz, M., Madrid, E., LuPiáñez, J., \& Tudela, P. (2003). High density ERP indices of conscious and unconscious semantic priming. Cognitive Brain Research, 17, 719-731.

Schneider, A., \& Shiffrin, R. M. (1977). Controlled and automatic human information processing: I. Detection, search, and attention. Psychological Review, 84, 1-66.

Schwartz, T. J., Kutas, M., Butters, N., Paulsen, J. S., \& Salmon, D. P. (1996). Electrophysiological insights into the nature of the semantic deficit in Alzheimer's disease. Neuropsychologia, 34, 827-841.

Shiffrin, R. M., \& SchneIder, W. (1977). Controlled and automatic human information processing: II. Perceptual learning, automatic attending, and a general theory. Psychological Review, 84, 127-190.

\section{NOTES}

1. Analyses with other cutoffs (e.g., $M \pm 2$ or $2.5 S D \mathrm{~s}$ ) or medians yielded the same patterns of results.

2. We performed the same analyses with the 6 oldest participants, whose mean age was 73.7 years (range, 69-82 years), to control for differences between age ranges, and we obtained the same RT and ERP patterns of results.

3. Priming effects remained significant even after trials with repeated numbers (e.g., prime SIX, target 6) were excluded from analysis, thereby excluding the contributions from repetition priming effects.

4. We tested the latency of the peak effect and obtained the same patterns of results (latency peaks for young participants, $395 \mathrm{msec}$ for incongruent trials and $385 \mathrm{msec}$ for congruent trials; latency peaks for older participants, $490 \mathrm{msec}$ for incongruent trials and $485 \mathrm{msec}$ for congruent trials).

5. This interaction, between age group and maximum difference between the ERP signals for the congruent and incongruent trials, was also significant for the time windows composed of the maximum difference in ERPs of $\pm 15 \mathrm{msec}$ or ERPs of $\pm 20 \mathrm{msec}$.

(Manuscript received April 16, 2004; revision accepted for publication April 15, 2005.) 